\title{
Wind Power Generation Situation and Research on Remote Monitoring Channel Program
}

\author{
Weijing Ma ${ }^{1, a}$, Fengjie Sun ${ }^{2, b}$, Xiaohong Duan ${ }^{3, c}$, Wenbing $\mathrm{Lu}^{4, \mathrm{~d}}$ and \\ Xiongwen Zhao ${ }^{5, \mathrm{e}}$ \\ School of Electrical and Electronic Engineering, North China Electric Power University, Beijing \\ 102206, China

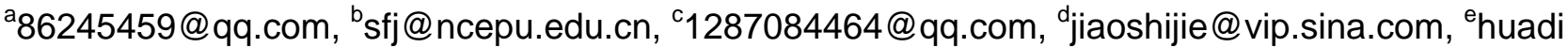 \\ an_zhaoxw@126.com
}

Keywords: Wind power; Remote Monitoring; ZigBee; GPRS; Routing Algorithm

\begin{abstract}
Wind energy can be converted to electric energy by wind power generation, which is the world's fastest growing renewable green energy. In this paper, in view of the current construction of wind power generation in Inner Mongolia, we study the technical status and development tendency of wind power. In order to improve the performance and efficiency of distributed wind power, this paper designs the monitor information transmission program based on ZigBee technology and GPRS networks and analyzes the dynamic network routing algorithm in monitoring node information transmission of wind turbine. At the same time, it creates favorable conditions for optimal operation and the wide use of wind power generation.
\end{abstract}

\section{Introduction}

Wind energy is an inexhaustible and environmentally clean energy, and various countries around the world have spent enormous efforts on researching and developing it in recent years. Inner Mongolia has rich wind resources which have a wide scale and good annual effective wind speed in continuity, so wind power development prospects are very broad.[1] Large wind turbines are enormous, located in remote broad regions and far away from the monitoring center.[2] Wind farms must improve their reliability, the efficiency and the life of generator sets in order to make it more competitive than other power plants . Therefore, it is significant to perfect the optimization of condition monitoring systems.

\section{Current Wind Power Construction Situation of Inner Mongolia}

Wind resource. According to the National Weather Service, China's wind power density is $100 \mathrm{~W} / \mathrm{m}^{2}$, the total reserves of wind energy resource are approximately $1.6^{*} 105 \mathrm{MW}$. According to the national effective wind power density, the effective wind appear time percentage and annual cumulative number of hours which the wind speed is not less than $3 \mathrm{~m} / \mathrm{s}$ and $6 \mathrm{~m} / \mathrm{s}$, the wind energy resources are divided into the following regions by concerned experts, as shown in table 1.

Inner Mongolia has vast territory and abundant wind energy resources, and it ranks 2nd among the wind energy resource areas in China. Wind energy resources in Inner Mongolia are mainly distributed in the typical steppe, desert steppe and desert areas. Development of wind energy resources in the region can be about 50\% of the total development in China. Wind energy resource reserve of Inner Mongolia ranks first in China.[1]

Existing installed capacity situation. The latest statistic data shows that wind power installed capacity of Inner Mongolia has reached 1848.86 kilowatt(KW) so far, accounting for $24.5 \%$ of national total wind power installed capacity, ranking first throughout the country. In 2013, Inner Mongolia's wind power generation capacity reaches 36.837 billion kilowatt-hour(KWH), accounting for $26.29 \%$ of national total wind power generating capacity, ranking first throughout the country. Wind power generation accounts for 10.17 percent of total region's electric generation capacity, and accounts for $16.88 \%$ of total region's electricity consumption. Besides, the level of wind power consumption of Inner Mongolia has reached the international advanced level. 
Table1 Classification standard of wind power area

\begin{tabular}{|c|c|c|c|c|}
\hline Area index & rich region & $\begin{array}{c}\text { Less rich region } \\
\text { II }\end{array}$ & $\begin{array}{c}\text { Available area } \\
\text { III }\end{array}$ & Poor area IV \\
\hline $\begin{array}{l}\text { Annual effective wind } \\
\text { power density }\left(\mathrm{w} / \mathrm{m}^{2}\right)\end{array}$ & $\geq 200$ & $200 \sim 150$ & $150 \sim 50$ & $\leq 50$ \\
\hline $\begin{array}{c}\text { Annual number of hours } \\
\text { which wind speed } \geq 3 \mathrm{~m} / \mathrm{s} \\
\text { (h) }\end{array}$ & $\geq 5000$ & $5000 \sim 4000$ & $4000 \sim 2000$ & $\leq 2000$ \\
\hline $\begin{array}{l}\text { Area percentage of } \\
\text { nationwide(\%) }\end{array}$ & 8 & 18 & 50 & 24 \\
\hline
\end{tabular}

In 2013, power grid of West Inner Mongolia completed wind power trough trading power 2.07 billion KWH with North China Power Grid. And power grid of East Inner Mongolia completed wind power temporary trading power 1.818 billion KWH with North China Power Grid.

Development and construction. Inner Mongolia ranks first in total reserves of wind energy in China, and it is one of the provinces of earlier development of wind power industry in our country. Inner Mongolia "Twelfth Five-Year" wind power development and access plan shows that the whole region plans to construct five millions of wind power bases and 10 wind test point areas. The goal of wind power development is that wind power capacity will reach more than 33 million KW in 2015, of which there are 20 million KW in West Inner Mongolia region and 13 million KW in East Inner Mongolia. Wind power key development areas are shown in table 2.

Table 2 Inner Mongolia "Twelfth Five-Year" development areas about wind power

\begin{tabular}{|c|c|c|c|c|c|}
\hline $\begin{array}{c}\text { Wind power } \\
\text { development bases }\end{array}$ & $\begin{array}{c}\text { Baotou, } \\
\text { Bayannur } \\
\text { Wind power } \\
\text { base }\end{array}$ & $\begin{array}{c}\text { Xilingol } \\
\text { Wind power } \\
\text { base }\end{array}$ & $\begin{array}{c}\text { Ulan Qab } \\
\text { Wind power } \\
\text { base }\end{array}$ & $\begin{array}{c}\text { Chifeng, } \\
\text { Tongliao } \\
\text { Wind power } \\
\text { base }\end{array}$ & $\begin{array}{c}\text { Huxing } \\
\text { Wind } \\
\text { base }\end{array}$ \\
\hline $\begin{array}{c}\text { Development } \\
\text { scale(MW) }\end{array}$ & 755 & 420 & 610 & 920 & 380 \\
\hline
\end{tabular}

Benefit analysis of wind turbines. Currently, there are 104 wind farms connected to the grid to run in West Inner Mongolia power grid. And green wind power has become the second largest of the main power supplies. In 2013, wind turbine efficiency of Inner Mongolia power grid is shown in table 3 .

Table 3 Inner Mongolia wind turbine efficiency in 2013

\begin{tabular}{|c|c|c|c|c|c|c|}
\hline $\begin{array}{c}\text { Installed } \\
\text { capacity(MW } \\
\text { ) }\end{array}$ & $\begin{array}{c}\text { Generating } \\
\text { capacity } \\
\text { (KWH) }\end{array}$ & $\begin{array}{c}\text { Utilization } \\
\text { time (h) }\end{array}$ & $\begin{array}{c}\text { Save standard } \\
\text { coal(million } \\
\text { tons) }\end{array}$ & $\begin{array}{c}\text { Reduce } \\
\text { emissions of } \\
\text { carbon dioxide } \\
\text { (t) }\end{array}$ & $\begin{array}{c}\text { Reduce } \\
\text { emissions of } \\
\text { sulfur } \\
\text { dioxide (t) }\end{array}$ & $\begin{array}{c}\text { Reduce } \\
\text { emissions of } \\
\text { NOx (t) }\end{array}$ \\
\hline 18486 & 36.837 & 2114 & 72.3 & 1595 & 1.8 & 3.5 \\
\hline
\end{tabular}

From the above description, we can see that Inner Mongolia has abundant wind resources. Under the guidance of the national policy, which encourages the development of wind power, the wind power of Inner Mongolia significantly accelerates the pace of construction. Because most of the wind turbines are installed in remote areas, perennially enduring wind force with irregular change, the impact of strong wind and extreme heat and cold temperature difference, which leads to many wind turbines failure in different forms. [3] Therefore, it is essential to design wind turbine remote condition monitoring channel programs to achieve wind turbines remote online monitoring, tracking, status recognition and control them operating energy efficient.

\section{The design of wind power remote monitoring information transmission channel}

Large wind turbine generators (WTG) are located in remote areas, and their distribution areas are wide and the number is large. So this paper designs a remote monitoring channel project for this issue. 


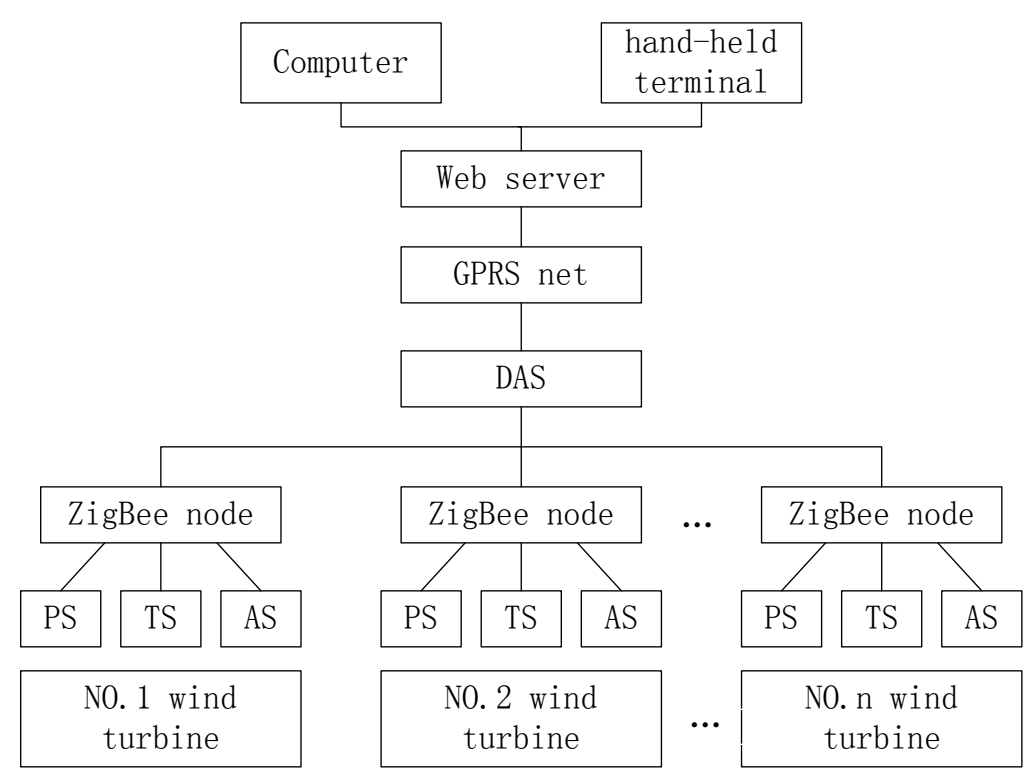

Figure 1 WTGS Remote Monitoring System Diagram

The requirement of wind power remote monitoring and analysis of information transmission means. According to the characteristics of local WTG scattered distribution and long-distance transmission of monitoring data, this design program mainly relies on ZigBee and GPRS technology in this paper.

Influenced by GSM network signal quality, the data transmission of GPRS exists a certain delay, so it cannot complete the synchronous data acquisition for multiple collection points. The networking of Zigbee is convenient, and its network signal quality is basically not affected by the outside world. When it sends acquisition command to all the ZigBee terminals, each terminal can simultaneously receive acquisition command, so as to complete the synchronization data acquisition for multiple collection points. It can not only achieve the long-range wireless data transmission, but also solve the synchronous data acquisition problem of acquisition points, through the combination of GPRS transmission with ZigBee network in the GSM network. Based on the above considerations, this paper develops a new remote distributed multi point monitoring system relying on GPRS. The framework of the system is shown in Figure 1.

System compositions of wind power remote condition monitoring. WTG remote condition monitoring system includes: data acquisition (DAQ), data transmission and remote monitoring section. The main function of each part are described as follows:[5]

(1) Data acquisition section

This section is responsible for data acquisition for each monitoring point. For this system, the major task is to collect vibration signal, temperature signal and pressure signal which are collected by AS (acceleration sensor), TS (temperature sensor) and PS (pressure sensor), in order to monitor the operational state of WTGS.

(2) Data transmission section

This section is responsible for receiving acquiring command from the remote server. After collecting the data, that data will be collected to the remote server. GPRS network coverage area is widespread, and users can easily and quickly use the GPRS service for remote network access at any time.

(3) Remote monitoring section

This section is responsible for sending and receiving commands and datum from the data transmission section. When the service has been completed, we will close the communication link between this new process and GPRS terminals, which means having completed a GPRS communication. 


\section{Analysis of dynamic network routing algorithm about information transmission of WTG monitoring nodes}

Analysis of information relaying transmission of WTG monitoring nodes. WTG monitoring data is mainly from the information monitored by the sensor on wind turbine blades. Wind turbine depends mainly on battery powered. If the receiving nodes close to wind turbines, the battery will change frequently which caused by the larger energy required for running, and it has disadvantage of battery maintenance and affects the life of the battery. Therefore, the receiving nodes and the wind turbines have a certain distance, which requires the nodes achieve ground connection through routing relay. For this problem, this paper uses the following dynamic network routing algorithm, based on the literature [6] and [7].

Analysis of ZigBee routing address assignment. ZigBee cluster tree routing, according to the relationship between the nodes, transmits message along the tree network topology. Coordinator assigns the node address through a distributed address allocation scheme, according to the number of nodes throughout the whole network: [6]

$$
C_{\text {skip }}(d)=\left\{\begin{array}{cr}
1+C_{m} \times\left(L_{m}-d-1\right), & \text { when } R_{m}=1 \\
\frac{1+C_{m}-R_{m}-C_{m} \times R_{m}^{L_{m}-d-1}}{1-R_{m}}, & \text { when } R_{m} \neq 1
\end{array}\right.
$$

Where: $d$ is the depth; $C_{\text {skip }}(d)$ is the address offset value between potential parent nodes on $d+1$ layer; $L_{m}$ is the maximum depth of the entire network; $C_{m}$ is the maximum node number of one parent node; $\mathrm{R}_{\mathrm{m}}$ is the maximum number of routing child node allowed by its parent node. By the formula (1) ,we can obtain address offset value $\mathrm{C}_{\text {skip }}(\mathrm{d})$ potential parent node $(\mathrm{ZR})$ on each layer , and its specific address An of child nodes is shown as follows:

$$
A_{n}=\left\{\begin{array}{l}
A_{\text {parent }}+C_{\text {skip }}(d) \times(n-1)+1, \quad \text { when } 1 \leq n \leq R_{m}, \quad Z R \\
A_{\text {parent }}+C_{\text {skip }}(d) \times R_{m}+n, \quad \text { when } 1 \leq n \leq\left(C_{m}-R_{m}\right), \quad Z E
\end{array}\right.
$$

Where: $A_{\text {parent }}$ represents the parent node address; $d$ represents the depth of the parent node; $n$ represents the number of nodes, and its range is $0 \leq \mathrm{d} \leq \mathrm{L}_{\mathrm{m}}$.

ZigBee routing algorithm includes the algorithm combined by basic AODV jr (AOD-VJunior) routing operation mechanism and Cluster-Tree address assignment.

Considering the node function and data transmission direction, , we can improve cluster tree routing algorithm, adopting measure the AODV jr routing algorithm combines with Cluster-Tree routing algorithm. And then it can solve the weakness of Cluster-Tree routing algorithm which lacks of flexibility, and can control well through the effectiveness of RREQ packet. Furthermore, it can solve the flooding problem that AODV jr routing algorithm finds a large quantity of packets generated by RREQ, which provides the optimal path for data transmission.

\section{Conclusions}

In this paper, we describe the state of wind power generation of in Inner Mongolia, and design remote monitoring channel program based on the geographical features of large-scale turbines. This paper adopts ZigBee note transmission and GPRS network transmission modes to transmit remote monitoring data, which can be a good way to achieve real-time monitoring of distributed wind power and cost and human resources saving. Meanwhile, this paper draws on the improved dynamic routing algorithm during the ZigBee nodes transmission, which increases the flexibility of the network and meets the low-cost, low-power, high-reliability design goals.

\section{References}

[1] Hu Hongbin, Zhang Deqiang, Li Ming et al. Inner Mongolia Wind Power Industry status and development trend [J]. Electric Manufacturing, 2013 (9): 61-63

[2] Wang Zhihua. Design of LabVIEW based condition monitoring and controlling operation system of MW wind power generator [D]. Shanghai Jiaotong University, 2009 
[3] Xie Yuan, Qiang Juexian. Condition Monitoring of Large-scale Megawatt Wind Turbines [J]. Journal of Shanghai Dianji University, 2009, 12 (4): 271-275

[4] Jiang Qian, Tang Hongru. Remote Monitoring System of Wind Power Generator Based on ZigBee technology [J]. Electrotechnics Electric, 2012 (12): 25-27

[5] Sun Limin, Wei Ran. Wireless remote monitoring system of wind power generator [J]. Mechanics and engineering application, 2012, 8:108-111

[6] Zhou Yue, Kan Fenglong, Zhang Dongwei, Shan Dan. A Wireless Sensor Networks Cluster Tree Routing Algorithm Based on ZigBee [J]. Journal of Shenyang Jianzhu University (Natural Science), 2011:391-396

[7] Yuan Anna. Research on Energy Balanced Routing Algorithm Based on ZigBee Network [D], Harbin University of Science and Technology, 2014, 3 